\title{
Managing Boundary-Spanning Cognition Through Emergent Problem- Framing in Enterprise Systems Design
}

\author{
Susan Gasson \\ Drexel University \\ sgasson@drexel.edu
}

\begin{abstract}
This paper presents findings from a study of the codesign of business processes and IT systems at the enterprise level. The findings suggest a punctuated equilibrium model of boundary-spanning design that is driven by a series of coordinating representations of the design problem-structure. These become more complicated as the design proceeds, adding new perspectives and dimensions to prior representations, and calling upon salient surface-structures that are helpful in conceptualizing the context of design. This finding challenges the notion of design as the exploration of deep organizational structures or as goal-driven design.
\end{abstract}

\section{Introduction}

Change projects involving the design of enterprise-spanning information systems (IS) create special problems for change managers as they combine the problems of spanning multiple domains or organizational practice - each of which has its own culture, values, and practices - with those of balancing business process change requirements with requirements for computer-based information systems design. While we may theorize boundary-spanning systems design as "the constant shaping of 'sociotechnical systems' in the form of design requirements that are attentive to and reflect the emerging interactions among people, software, and technologies," [1], this description fails to explain how we should approach boundary-spanning IS design in practice.

\section{Conceptual underpinnings}

Boundary-spanning design involves coordinated sensemaking across a variety of stakeholders and participants, each of whom interprets organizational problems and solutions according to their role in an intersecting set of participation frameworks - the professional practices, socio-cultural values and norms that govern work in various organizational knowledge domains [2]. Organizational IS design may be understood as an emergent change process, achieved through the gradual realignment of information systems to fit with emerging business strategy in response to changes in its operating imperatives and external business environmental [3]. IS design may alternately be conceptualized as a process of punctuated equilibrium, defined as periods when stable organizational structures constrain radical change, punctuated by brief transitions that introduce disruption and upheaval to the status quo [4]. Drawing on paleobiology, punctuated equilibrium relies on the idea that complex organizational systems are stabilized by some underlying order, or "deep structure" [5, 6]. Deep structure in organizations reflects political centers of power, socio-cultural practices and values, control-systems, and technology configurations [6]. It is difficult to change deep structure because of the trail of strategic choices create a "sunk cost" imperative to justify the existing organization [4]. Deep structure reflects the mutual reinforcement that results from ongoing organizational enactment [7]. "The deep structure is what confines change during equilibrium periods to variations on an enduring theme - and it is also what 'disassembles, reconfigures, and enforces wholesale transformation during revolutionary punctuations"” [4].

Organizational participants interact with its deep structure through a "surface structure", a set of features and interfaces provided by organizational information systems. These provide generative configuration mechanisms for organizational and IS design [5]. So we may conceptualize IS change as "complex, multi-level, episodic change where simultaneous processes interact creating unpredictable and dynamic change outcomes" [8, p.592]. The generative change needed for Enterprise System design may come about because of a continuous adjustment, as the surface structure provided by the system is seen as misaligned with strategic change imperatives - for example, the need for company vs. competitor sales reporting in response to increased 
competition in the marketplace. Or it may result from a series of episodes and transitions, which advance the design or reveal areas where the deep structures of organization been poorly understood [8]. The first research question thus explores the design process:

RQ1: What process model best describe boundaryspanning, information system design in the wild - and how does this operate?

To understand how deep and surface structures are understood by IS design participants, I employ the epistemological lens of social cognition, where individuals employ cognitive frames or mental models that reflect their experiential knowledge (a.k.a. technological frames, when these are applied to group perceptions of the role, use, or impact of technology) [3]. Sensemaking in boundary-spanning collaboration is effected through the use of epistemic objects, such as design models and specifications that allow understanding to be explored through representation [9] and boundary objects that allow knowledge specific to one participation framework to be translated across domain-boundaries without design participants needing to understand every aspect of the participation framework of others [10]. A multi-level analysis is required as individual framing of design requirements may align or conflict with intersubjective (shared by the design group) frames, which may in turn be different than generically subjective frames that reflect group or organizational consensus ("what we all know”) [3, 7, 11]. "Organized sensemaking" occurs as actors collaborate on interpreting organizational structures and the changes required to make these work for the situation at hand. Groups of change agents jointly construct design frames through three stages of distributed sensemaking: (i) enactment, where participants perform a course of action that creates or reinforces organizational structures, (ii) selection of organizational narratives used to interpret the situation, and (iii) retention where frames that align with group perspectives are operationalized into methods for future design [7]. The second research question thus explores distributed sensemaking:

RQ2: What is the process by which design team participants collaborate in framing, exploring, and agreeing design problems and solutions?

\section{Research site and method}

\subsection{Research site}

The ethnographic study presented here explores the organizing and framing processes of a group of strategic senior managers engaged in the definition of financial and enterprise systems in a U.S. University, over a period of two years. The University is a private, 4-year degree granting institution, well regarded in its region. It offers a wide variety of majors in Business, Communication Studies, Education, Fine \& Performing Arts, Healthcare \& Sports Sciences, Humanities, Social Sciences \& Psychology, Natural Sciences, and Pre-Med. The University employed an Enterprise System that was used by many similar academic institutions, but which had not been fully implemented. Several functional groups, in particular Human Resources, were suspicious of the introduction of an overarching administration system, viewing this as an attempt to impose control over their group culture and existing practices.

The Design Taskforce was assembled in response to a perception that the University's Enterprise Systems (ES) were inadequate for financial management and reporting. Taskforce participants included all of the major organizational managers: the Dean of Academic Affairs, the Executive Director of Student Accounts, Director of the Office of Student Accounts, the University Registrar, and Associate Registrar, the Dean of Finance \& Operations, the Director of Financial Aid, the Financial Systems Manager, the Coordinator of Special Projects for the University, the Director of Marketing, and the Director of Information Services. Ad hoc participation was invited from all actors and groups affected by the current area of operational focus and included a senior system analyst whose role was to formalize design requirements for changes to the Enterprise System. Taskforce members were involved in a collective process of Enterprise System redesign that had recently started when I was invited to join the team for the research study. They met monthly, to discuss issues and to define what requirements needed to be resolved by members before the next meeting.

\subsection{Research method}

I employed a participant observation approach to ethnography, over a period of two years. Initially, I observed and recorded meetings of the Enterprise Systems Taskforce, to acculturate myself to the content and context of the change initiative. I attended monthly meetings of the Taskforce, interviewed the regular participants to understand how they understood and defined project objectives, and what problems they perceived with defining a joint design. After the first two meetings, I met with participants again to map out the processes that they perceived should be managed by the Enterprise System. I explored the key decision-points where boundaryspanning coordination was required across domains. These were used to suggest issues for discussion in group meetings. I interacted regularly with meeting 
participants, discussing their analysis and activities between meetings, and reviewing progress with the Information Services Manager, who led the design initiative. During episode 6, I facilitated a systemic analysis workshop with the Taskforce, using Soft Systems Methodology (SSM) techniques to map suggested system solutions and employing a systemic problem analysis to explore problem interdependencies between workgroups [2]. The workshop involved the main participants and a number of influential decision-makers including the University President, in processes of problem surfacing and exploration. These were effective at achieving a shared perspective and resulted in a cohesive, shared model of the change goals, moving forward. Following that point, I attended meetings as an ethnographic observer until the Enterprise System change requirements were defined and implemented.

\section{Findings}

\subsection{Framing change goals}

The main issue facing the Taskforce was how to manage the introduction of new degree programs. There was a wide variation in how participants defined the problem, shown in Table 1 . The only point of agreement across Taskforce members was that strategic planning was influenced too much by opportunities offered by community interest groups and international non-government organizations (NGOs). This was seen to lead to many of the other problems listed. Taskforce members tried - and failed - to define a cohesive set of processes and a supporting Information System that would resolve these issues without overly constraining the flexibility to serve local community organizations with rigorous degree programs that were tailored to their needs - a strategic University goal. The disruptions that led to agreement that the Enterprise System needed to be updated to support program creation and student enrollment more effectively was the realization that the program creation guidelines and program evaluation processes were not being used. Executive decision-makers did not plan new program designs around the credit requirements for students to qualify for Financial Aid, recruiters ignored enrollment deadline constraints in order to maximize their rewards (they were paid for the number of students recruited), and Admissions staff enrolled students at the last minute to ensure the financial viability of a new academic program. This led to the creation of a new ES Taskforce, to explore what changes needed to be made to the enterprise system in order to formalize, control, and coordinate program creation, admissions, and student enrollment.

Table 1. Problem-Frames of Key Taskforce Stakeholders

\begin{tabular}{|l|l|l|}
\hline Stakeholder & Problem framing & Nature of problem \\
\hline $\begin{array}{l}\text { Information Services } \\
\text { Group }\end{array}$ & $\begin{array}{l}\text { a strategic } \\
\text { management issue }\end{array}$ & $\begin{array}{l}\text { because strategic management is entrepreneurial, new programs are } \\
\text { announced before the various administrative groups have time to evaluate } \\
\text { the implications or prepare for program administration }\end{array}$ \\
\hline $\begin{array}{l}\text { University Registrar } \\
\text { \& Admissions Mgr. }\end{array}$ & $\begin{array}{l}\text { administrative } \\
\text { issue }\end{array}$ & $\begin{array}{l}\text { students are often recruited to programs for which no classroom location, } \\
\text { instructor, or facilities are available }\end{array}$ \\
\hline Dean of Finance & $\begin{array}{l}\text { an admissions } \\
\text { management issue }\end{array}$ & $\begin{array}{l}\text { students are recruited at the last minute in order to ensure the program's } \\
\text { financial viability, so there was a high degree of uncertainty about class sizes }\end{array}$ \\
\hline $\begin{array}{l}\text { Financial Aid } \\
\text { Administrators }\end{array}$ & $\begin{array}{l}\text { a strategic } \\
\text { management issue }\end{array}$ & $\begin{array}{l}\text { because strategic management is entrepreneurial, degree programs are } \\
\text { scheduled at the last minute - these fail to meet financial aid eligibility } \\
\text { requirements (e.g., the number of instruction weeks in specific academic year) }\end{array}$ \\
\hline $\begin{array}{l}\text { Manager of Student } \\
\text { Support Services }\end{array}$ & $\begin{array}{l}\text { administrative } \\
\text { issue }\end{array}$ & $\begin{array}{l}\text { Recruiters promise students that they will be eligible for financial aid, even } \\
\text { when this has not been confirmed - the University needs to meet any } \\
\text { shortfall in funding }\end{array}$ \\
\hline $\begin{array}{l}\text { Director of } \\
\text { Information Services }\end{array}$ & $\begin{array}{l}\text { logistical } \\
\text { management issue } \\
\text { insufficient time for these to be ordered }\end{array}$ \\
\hline
\end{tabular}

\subsection{Coordinating shared task goals}

The process-timeline for introducing a new program, shown in Figure 1, provided a coordinating object for the group design. This took the form of an abstract "script" to explore the work of various operational groups around a standardized calendar. The loose alignment provided by the timeline allowed members of each workgroup to attach their own information needs and procedures to the timeline without it conflicting with individual perspectives.

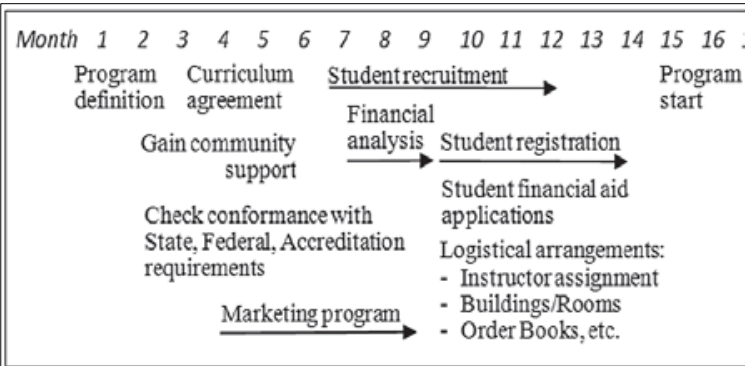

Figure 1. New Program Process Timeline 
Table 2. Coordinating Objects Used By Key Stakeholder Groups

\begin{tabular}{|l|l|l|}
\hline Stakeholder Group & Key Issue(s) & Purpose of shared student status spreadsheet \\
\hline $\begin{array}{l}\text { Information } \\
\text { services group }\end{array}$ & $\begin{array}{l}\text { Coordinating rapidly changing information about } \\
\text { student and program arrangements that the } \\
\text { Enterprise System cannot manage }\end{array}$ & $\begin{array}{l}\text { Order printed materials \& reserve rooms for } \\
\text { classes in advance of formal registration }\end{array}$ \\
\hline University registrar & $\begin{array}{l}\text { ensuring that students are registered in time for } \\
\text { the degree start }\end{array}$ & $\begin{array}{l}\text { Update status as students complete each stage } \\
\text { of application and registration }\end{array}$ \\
\hline Financial Aid Group & $\begin{array}{l}\text { processing and validating financial aid } \\
\text { applications prior to registration }\end{array}$ & Check student eligibility for financial aid \\
\hline $\begin{array}{l}\text { Financial } \\
\text { Controller's Office }\end{array}$ & $\begin{array}{l}\text { ensuring that the new program is economically } \\
\text { viable in advance of its start }\end{array}$ & Anticipate class size \\
\hline $\begin{array}{l}\text { Information } \\
\text { Technology }\end{array}$ & $\begin{array}{l}\text { Requirements analysis for changes to the } \\
\text { Enterprise System }\end{array}$ & $\begin{array}{l}\text { Attempting to codify spreadsheet info. fields } \\
\text { to define system functionality }\end{array}$ \\
\hline
\end{tabular}

The process of agreeing which information needs would be met by the Enterprise System was contentious, with many group's requirements being rejected by the Information Services Manager as "not related to program creation.” Disruption to the group consensus introduced by this standardized Process Timeline arose when the model was proposed to faculty committees for use. Feedback from faculty demonstrated that the standardized timeline only "worked" to coordinate business processes because it excluded enterprise system workarounds employed by each group involved in implementing new programs. Various groups employed a local spreadsheet of student-status to track rapidly-changing information that the Enterprise System could not provide. This was updated with additional information by each group and maintained locally, so it contained inconsistent status indicators across the various groups using this information, as shown in Table 2. When the IT analyst collecting ES change requirements could not reconcile various workgroup versions of the spreadsheet, the Taskforce realized that they needed to formalize the information used to plan new academic programs.

\subsection{Defining shared program categories}

A Taskforce workshop was held to explore how the "big picture" of program administration was coordinated across all affected stakeholder groups. Each group framed a number of special cases and multiple disagreements arose around which should be accepted as legitimate procedures. The aggregated set of special cases complicated the flowchart so much that no-one could understand the process flows. In a subsequent brainstorm session, Taskforce members brainstormed how to categorize the special cases. They converged on a solution of standardizing the format of new academic programs, by type. Taskforce members identified four different types of program calendar: Semester Programs, Certificate Programs, Quarter Programs, and Ad Hoc Programs. A new University Calendar, shown in Figure 2, was defined around these program formats. Start-date ranges for each type of program were defined and all activities required before a program could start were mapped out, to define the lead time required for program introduction and design for each category. The student accounts and financial aid groups were especially active in this episode, leading discussions about standardization needs and explaining their information requirements in great detail. When the standardized calendar was introduced, it appeared to have an immediate effect. Operations to coordinate work between groups were simplified. Student aid issues were reduced. The longer planning lead times were perceived as producing higher quality academic programs. But as the administrative year proceeded, there appeared to be an increasing number of exceptions to these program formats. New exceptions were defined to accommodate legacy programs, or to meet the needs of specific community programs.

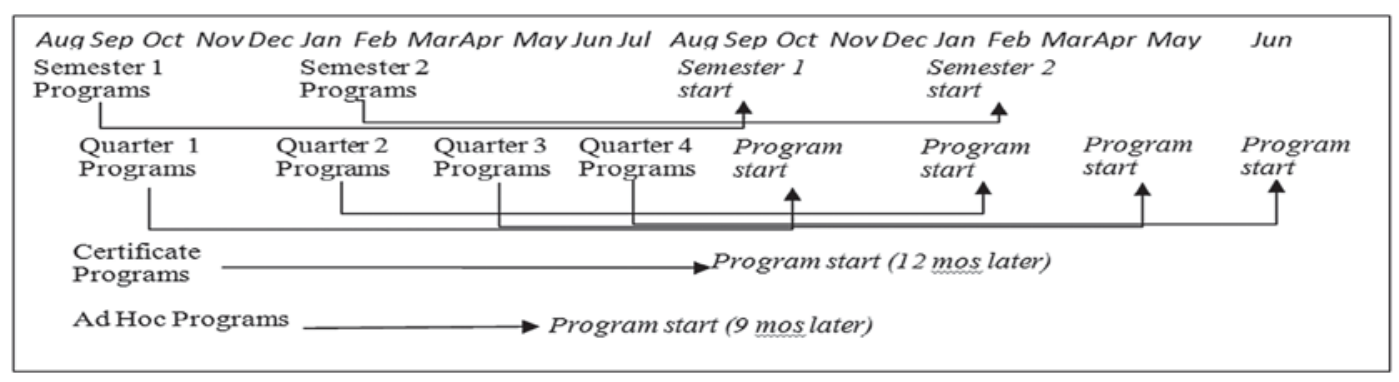

Figure 2. The Process Timeline (Calendar) For New Program Lead-Time, By Category 
The disruption to this episode of coordination around a standardized program format occurred because of increasing tensions between the regulating influence of the "standardized" program formats and the way in which new program requirements evolved to fulfill the community support aspects of the University mission. Many new programs did not conform to a standardized format and there was increasing dissatisfaction from strategic planners that University strategy was being impeded. Both the Executive Committee and the University President were pushing for an expansion of the University's strategic plan to take advantage of opportunities offered by private funding agencies and to expand outreach to underserved areas of the U.S. This led to rising tensions around how it could be accommodated.

\subsection{Informal system boundary expansions}

After a series of major disagreements, the constraints of four standardized program formats were rejected. New programs were created that did not accord with these formats and that had shorter lead times than required for effective planning. The various groups represented on the Taskforce agreed that they would implement contingency procedures to deal with exceptions. Taskforce approval of these contingencies expanded the business process boundary implicitly, by adopting a series of contingency procedures defined through short-term "interfaces" to external groups and systems. The implications of this expanding information system boundary were slow to be realized. The increasing complexity of operations was obscured by the information services group, who developed short-term workarounds for each group. They made phone calls to warn student services that action was required, provided interim calculations of student numbers to the registrar's office, and fed student data to the financial aid office for aid application processing and to the financial controller's office for planning purposes. In effect the information services group became a de facto coordination system, operationalizing the implicit frames of various Taskforce members to bypass the formal Enterprise System and develop workarounds to formal business processes based on the standardized calendar.

The eventual disruption occurred with the realization that many new programs did not conform to the credit or delivery requirements agreed with the national accreditation board. The majority of new programs needed last-minute changes to the curriculum to conform with accreditation requirements. When the group mapped out planning procedures for new programs, they were shocked to discover how much more complex these had grown since the institution of the standardized program calendars. It proved impossible to model a set of standard procedures for the new programs. There were so many special cases that the director of information services observed that they were modeling "a calendar per academic program.” The Financial Controller became concerned that the true costs of each program were not being accounted for and suggested they attempt to standardize accounting for program costs.

\subsection{A shared cost-reconciliation frame}

The Taskforce decided that the calendar approach to evaluating programs had introduced a false sense of security. They adopted a standardized form of program cost structure as their solution. The program cost structure embodied a key concern - that programs were being expanded without any analysis of the cost implications - but it also provided a framework for coordinated change. An activity-based analysis of indirect program costs was performed by each group involved. This revealed the shocking cost implications of various types of program expansion. Various Taskforce members volunteered to discuss cost implications with individual Deans, with strategic managers, and with other stakeholders, in order to manage the political and organizational consequences of standardization. An "informal cost structure" form presented a new coordinating object for the group, as various Taskforce members volunteered to investigate the costs of time and resources spent on ad hoc program workarounds. Taskforce members were continually surprised by the totals reported as they analyzed the detailed costs of their failure to standardize the University calendar. These totals made a huge impression on strategic managers - the University President instructed the Taskforce to "take control of the situation.” But it was clear that the key problem lay with executive decision makers, who continued to propose nonconforming, ad hoc programs. The Taskforce could reach no conclusion about how to deal with this.

Disruption to the cost-reconciliation frame came with the news that accreditation was threatened by the failure of recent academic programs to meet accreditation requirements. The lack of conformity with calendar credit requirements, national evaluation, and quality criteria had led to pressure from a major undergraduate program accreditation board. There were several heated meetings, as Taskforce members debated how to manage the situation and who should take responsibility for change. In the end, the University registrar took control of the situation and met with the president to discuss how to manage the situation. 


\subsection{The power of external threats}

The Taskforce received instructions from the executive board to explore what needed to happen for the University to standardize around a single program calendar. Taskforce members now worked on a universal set of procedures that would formalize coordination across the various groups involved in program administration. The external crisis instilled a new sense of urgency and cooperation. Each workgroup defined changes to the Enterprise System that were required for coordination across domains. For example, the financial aid office modeled the work that they did, to justify their need for twelve weeks' notice of individual student registrations prior to start of the academic program year. The Student Services group mapped out the multiple interactions between their processes and student registration status, to justify why they needed advance warning of student enrollments. Even when changes were not agreed by the Taskforce, they had established a much better understanding of others' work processes and this assisted with negotiations. Standardized procedures and templates were created rapidly for new program planning, based on the Taskforce's accrued learning. A "will not be approved without this" framing provided a motivating script for the framework!

Disruption to the strategic planning and coordination frame came about when the introduction of the standardized program approval framework caused problems. Recruiters felt that they were being cheated of the opportunity to recruit late students, and compromises had to be made to keep them on board. Executive decision makers had to be reminded of the implications of abandoning the standardized calendar and procedures whenever they attempted to do so under pressure from community organizations to provide open-access programs. There were ongoing tensions between the needs of accreditation, conformance, and the University mission to provide open access to education.

\subsection{Surfacing misunderstandings}

Tensions between external threats and strategic goals were resolved by the Information Services director, whose group had devised the workarounds that had previously caused so many problems. They developed an informal cost estimation system (a detailed spreadsheet) that reflected the activity-based costs of introducing a new academic program, based on estimates generated during cost-reconciliation. Each time a new program was planned, the cost estimation spreadsheet was used to reflect the true costs of introduction. This exposed the costs of deviations from the standardized calendar formats, reducing these to almost nil. By disrupting the strategic mission frame ("open access requires responsive, ad hoc program creation") with an adapted version of the cost-reconciliation model, the Information Services group was able to introduce a collective breakdown that made the group realize that they genuinely needed to formalize their "standardized program approval" procedures by defining changes to the Enterprise System design - which was why the Taskforce had been assembled. These enabled the Enterprise System to track formal program planning, manage new program administration, and to support the informal practices required for program planning and student recruitment to work. The external accreditation board was satisfied that the University's programs were now stable and well managed. Student satisfaction also increased, as financial aid application was simplified and became more certain. Not least, the cost structure of programs was reduced drastically, providing major benefits to the University and allowing it to fulfill its mission more effectively.

\subsection{Meta-analysis of design processes}

The design project proceeded as a series of seven episodes, described here and analyzed in Table 3.

Episode 1. The first coordinating object provided a program proposal (document) template to provide a "bare bones" outline of the information needed by each group involved in the planning process. The template proved inadequate, as it was often left incomplete due to time constraints with submission.

Episode 2. A revised coordinating object employed a timeline model to track the information requirements of new program planning processes by lead-time. This representation was selected to support the problemframe of ensuring that all groups had the requisite information to plan their work in advance of new program introduction. But it failed in practice, when it was discovered that each group had a different version of an interim student registration status spreadsheet, that allowed them to contact or account for students in advance of formal registration. The result was a conflicting set student tracking requirements, which were difficult for people from other workgroups to reconcile. Many were dismissed as not necessary, only to be reinserted when Taskforce members had a more integrated appreciation of how the program planning process needed to work across domains and time.

Episode 3. Failure to understand the Enterprise System workarounds employed by each group led to the adoption of another coordinating object, this time representing the various categories of program planning and attempting to develop the timeline 
calendar model of episode 2, to account for these cases. The program categorization framework broke down when it could not accommodate all of the special cases needed for legacy programs, or emerging forms of open access degree programs.

Episode 4. The program categorization framework was replaced by an attempt to model and formalize contingency procedures to deal with exceptions to the standard program categories. The coordinating object representation not only complicated the previous one, but also incorporated a new coordination and control mechanism, as contingency procedures were controlled by the Information Services group to centralize the coordination of new program planning. This was undermined by the realization that the centralized controls were creating even more work for administrators, as the new programs did not conform to accreditation requirements, triggering last-minute revisions to their schedule and delivery plans and increasing the cost of program creation.

Episode 5. The group complicated their problem representation again, reframing the problem to capture the cost of system and process workarounds and compare it to an ordered planning process. The resulting cost estimates shocked everyone - the cost of workarounds increased new program costs significantly. The cost-reconciliation process revealed flaws in the assumptions underlying previous cost estimation structures, leading to several programs being abandoned before they were introduced. The cost-basis problem-frame was disrupted in this episode due to an external threat.

Episode 6. The failure of new programs to conform with calendar credit requirements, national evaluation standards, and quality criteria had led to pressure from a major undergraduate program accreditation board to standardize program schedule planning. This, combined with the cost-structures uncovered during reconciliation of the informal and formal activity-costs during episode 5 , led the Taskforce to return to a single planning calendar and timeline. They extended this by adding standardized processes to monitor and coordinate planning with executive decision makers, who were convinced of the need to conform to a standardized program design by the external threat of losing accreditation.

Episode 7. The recognition by executive decisionmakers of the need for control and standardization permitted the planning processes to be formalized and integrated into the enterprise system. By now, these processes were well-understood across the various stakeholders and knowledge domains involved, so IS change requirements could be defined in detail from the standardized process and information needs defined in episode 6 and validated in episode 7.

\section{Discussion of findings}

\subsection{Boundary-spanning design as punctuated equilibrium}

This section addresses [RQ1] What process model best describe boundary-spanning, information system design in the wild - and how does this operate? From the summary in Table 3, the design process fits well with a punctuated equilibrium model of system design, organized around coordinating objects that reflected an emergent understanding of the organization's "deep structures" $[4,6,11]$. The coordinating representations and problem-frames employed in each episode indicate an emergent understanding of design objectives, scope, and deliverables, which was mediated by attempts to model surface structures that were salient to each episode of design [5]. The literature views disruptive critical incidents as largely resulting from external, environmental pressures [4, 6, $8,12]$. But, with one exception, the critical incidents disrupting each episode of design were internal, resulting from a misalignment of the surface structures (represented by the coordinating objects created for collective framing of the problem-space) with organizational deep structures that were only partly understood by each individual. Each episode's coordinating object model builds on the previous one, to provide a successively more complex model of the salient parts of the organization's deep structure. The "complication role" of coordinating objects allowed them to coordinate group activity around a collective and distributed form of experiential learning, as various permutations of surface structure became the subject of design-group experimentation cycles, as shown in Figure 3.

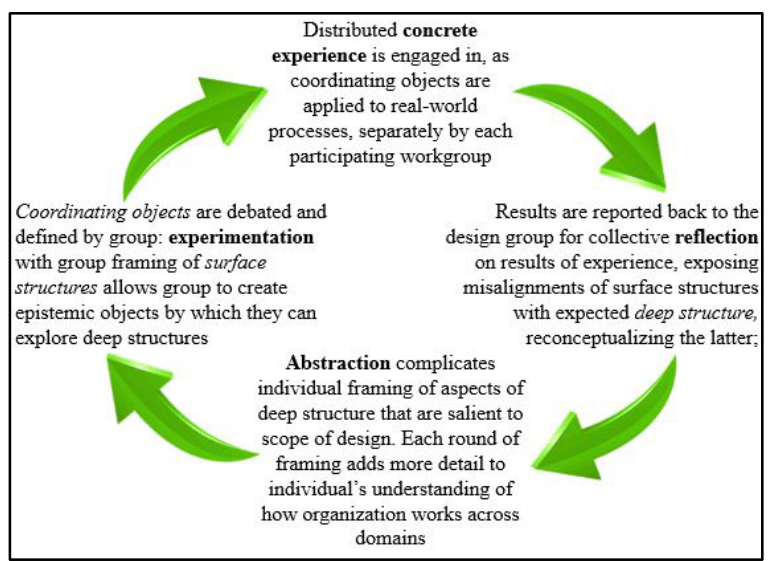

Figure 3. Distributed Design Learning Cycle

The exception to the internal source of disruptive critical incidents came when the University's degree accreditation was threatened. This created immediate and radical disruption, that led to deep learning. 
Table 3. Coordinating Objects Used By Key Stakeholder Groups

\begin{tabular}{|c|c|c|c|c|}
\hline Ep./Problem Frame & oordinating object & Group Problematization & Business Process Changes & \\
\hline $\begin{array}{l}\text { 1. Coordinating } \\
\text { process } \\
\text { management }\end{array}$ & $\begin{array}{l}\text { New program proposal } \\
\text { template constrains and } \\
\text { regulates strategic } \\
\text { management's } \\
\text { entrepreneurial activity }\end{array}$ & $\begin{array}{l}\text { Define templates, forms, } \\
\text { and procedures for new } \\
\text { program creation and }\end{array}$ & $\begin{array}{l}\text { Standardize program } \\
\text { creation \& student } \\
\text { recruitment procedures } \\
\text { Ensure student plan of } \\
\text { study meets credit reqs. }\end{array}$ & $\begin{array}{l}\text { Create informal } \\
\text { guidelines; New forms \& } \\
\text { procedures } \\
\text { Eval. criteria defined for } \\
\text { Program Review Cttee }\end{array}$ \\
\hline Disruption & \multicolumn{4}{|c|}{$\begin{array}{l}\text { Program proposal in complete: (i) Executive decision-makers do not ensure program of study will satisfy } \\
\text { accreditation/financial aid requirements before signing contracts; (ii) Recruiters ignore enrollment timeline } \\
\text { constraints: faculty, rooms, book, computer orders changed at last minute }\end{array}$} \\
\hline $\begin{array}{l}\text { 2. Need to } \\
\text { constrain } \\
\text { entrepreneurial } \\
\text { activity of } \\
\text { strategic } \\
\text { management and } \\
\text { planners }\end{array}$ & \begin{tabular}{|l|} 
Program proposal \\
timeline constrains \\
improvisation in new \\
program design. \\
It also coordinates \\
information flows \\
between each group's \\
work processes.
\end{tabular} & $\begin{array}{l}\text { Identify program } \\
\text { evaluation criteria: } \\
\text { *Enrollment meets goals? } \\
\text { *Meets accreditation reqs.? } \\
\text { *Meets fin. aid credit reqs? } \\
\text { *Student enrollment nos. } \\
\text { confirmed early enough to } \\
\text { arrange course logistics? }\end{array}$ & $\begin{array}{l}\text { Coordinate info. flows: } \\
\text { Program goals \& strategy } \\
\rightarrow \text { outreach } \rightarrow \text { recruit } \\
\rightarrow \text { financial viability } \\
\text { Curriculum } \rightarrow \text { accred. \& } \\
\text { fin. aid reqs. } \rightarrow \text { marketing } \\
\text { Recruit } \rightarrow \text { admissions } \rightarrow \\
\text { registration } \rightarrow \text { logistics }\end{array}$ & $\begin{array}{l}\text { Formal timeline does } \\
\text { not include student } \\
\text { status info. required by } \\
\text { various admin. groups. } \\
\text { Attempts to formalize } \\
\text { student status fails, as } \\
\text { too many variations }\end{array}$ \\
\hline isrup & \multicolumn{4}{|c|}{$\begin{array}{l}\text { Collective realization that timeline only works when it excludes detailed logic of workarounds employed by } \\
\text { each major domain group; Workarounds use student enrollment status spreadsheet } \rightarrow \text { defines lead-time } \\
\text { for key decisions; require intermediate student status reports }\end{array}$} \\
\hline $\begin{array}{l}\text { Agree shared } \\
\text { rog. categorizatio } \\
\text { cheme that } \\
\text { efines program } \\
\text { alendars }\end{array}$ & $\begin{array}{l}\text { Program intro. processes } \\
\text { modeled to integrate } \\
\text { info. from each group's } \\
\text { informal work sheet; } 4 \\
\text { program types defined }\end{array}$ & \begin{tabular}{|l|} 
Define start-date ranges \\
when each program type \\
can meet accreditation \& \\
financial aid reqs. to define \\
each program's lead-time
\end{tabular} & $\begin{array}{l}\text { New program acceptance } \\
\text { criteria now include start- } \\
\text { date and lead-time } \\
\text { constraints for each of } 4 \\
\text { program types. }\end{array}$ & $\begin{array}{l}\text { Managed by defining } \\
\text { deadlines for review by } \\
\text { various committees or } \\
\text { admin. groups. }\end{array}$ \\
\hline isruption & \multicolumn{4}{|c|}{$\begin{array}{l}\text { Program categorization framework breaks down when it cannot accommodate the special cases needed } \\
\text { for many legacy programs, or the emerging needs of new community degree programs driven by University } \\
\text { strategy of expanding open access to education }\end{array}$} \\
\hline $\begin{array}{l}\text { eal with } \\
\text { xceptions to } \\
\text { tandard program } \\
\text { ategories }\end{array}$ & $\begin{array}{l}\text { Info. Services Group } \\
\text { communicates student } \\
\text { enrollment \& status } \\
\text { changes to admissions, } \\
\text { student services, } \\
\text { registrar, financial aid, } \\
\text { and financial controller }\end{array}$ & $\begin{array}{l}\text { What do we need to do, to } \\
\text { ensure program conforms } \\
\text { to accreditation, financial } \\
\text { aid requirements? } \\
\text { How do we assess } \\
\text { program financial viability? }\end{array}$ & \begin{tabular}{|l|} 
The formal system of \\
work-activity is expanded \\
through short-term \\
"interfaces" to external \\
groups and systems to \\
accommodate non- \\
conforming programs
\end{tabular} & $\begin{array}{l}\text { Info. Services group } \\
\text { becomes de facto } \\
\text { coordination system, } \\
\text { bypassing Enterprise Sys } \\
\text { Informal system: emails } \\
\& \text { phone calls used for } \\
\text { calendar workarounds }\end{array}$ \\
\hline isruption & \multicolumn{4}{|c|}{$\begin{array}{l}\text { New programs do not conform to credit/delivery requirements agreed with accreditation board, need to } \\
\text { be updated before introduction. Taskforce cannot integrate all special cases into standard calendar or cost } \\
\text { model (need to model "a calendar per academic program"). }\end{array}$} \\
\hline $\begin{array}{l}\text { Employing a cost } \\
\text { econciliation }\end{array}$ & \begin{tabular}{|l|} 
Standardized cost- \\
structure provides a \\
framework to explore \\
info. \& activity reqs. for \\
new program. Activity- \\
based cost analysis \\
accounts for indirect and \\
direct program costs
\end{tabular} & $\begin{array}{l}\text { What are workaround } \\
\text { costs for new programs? } \\
\text { How much time/effort } \\
\text { does each group spend to } \\
\text { perform ad hoc work } \\
\text { needed to ensure } \\
\text { programs are financially } \\
\text { and academically viable? }\end{array}$ & \begin{tabular}{|l|} 
Taskforce members \\
investigate costs of time \\
and resources spent on \\
ad hoc programs. \\
Financial controller \\
calculates total costs of \\
program planning \\
revealing estimate flaws
\end{tabular} & $\begin{array}{l}\text { Informal cost structure } \\
\text { replaces direct cost } \\
\text { structure in strategic } \\
\text { decision making, to } \\
\text { account for real costs of } \\
\text { new program } \\
\text { introduction - total cost } \\
\text { shock everyone! }\end{array}$ \\
\hline & \multicolumn{4}{|c|}{$\begin{array}{l}\text { EXTERNAL THREAT: The failure of new programs to conform with calendar credit requirements, national } \\
\text { evaluation, and quality criteria leads to pressure from a major undergraduate program accreditation board } \\
\text { to fix programs, or lose accreditation status. }\end{array}$} \\
\hline $\begin{array}{l}\text { 6. Explore } \\
\text { needs to ha } \\
\text { for Universi } \\
\text { standardize } \\
\text { program m } \\
\text { around a sir }\end{array}$ & $\begin{array}{l}\text { Strategic planning and } \\
\text { coordination around a } \\
\text { single academic calendar, } \\
\text { with two variations } \\
\text { (semester and quarter) } \\
\text { and a uniform start week } \\
\text { for all programs }\end{array}$ & \begin{tabular}{|l} 
Taskforce explores how \\
workflows in one group \\
create or resolve \\
problems in other groups, \\
resurrects ill-understood \\
problem frames rejected \\
in earlier design episodes
\end{tabular} & $\begin{array}{l}\text { Taskforce maps out } \\
\text { universal procedures \& } \\
\text { lead-times to coordinate } \\
\text { formal and informal wor } \\
\text { involved across groups to } \\
\text { create, evaluate, \& } \\
\text { manage a new program }\end{array}$ & $\begin{array}{l}\text { Formal procedures } \\
\text { are codified to the } \\
\text { extent that these can } \\
\text { be incorporated into } \\
\text { the formal Enterprise } \\
\text { System }\end{array}$ \\
\hline Disruption & \multicolumn{4}{|c|}{$\begin{array}{l}\text { Standardized program approval framework causes problems: Recruiters feel they are cheated of } \\
\text { opportunity to recruit late students. Executive decision makers are under pressure from ext. community } \\
\text { organizations to provide non-conforming, open-access programs and need to be monitored carefully. }\end{array}$} \\
\hline $\begin{array}{l}\text { 7. Coordinating } \\
\text { program } \\
\text { planning across } \\
\text { workgroups via } \\
\text { standardized } \\
\text { procedures. }\end{array}$ & $\begin{array}{l}\text { Mandatory standardized } \\
\text { procedures \& templates } \\
\text { created for new programs } \\
\text { and courses. } \\
\text { Without conformance to } \\
\text { these, programs will not } \\
\text { be approved. }\end{array}$ & $\begin{array}{l}\text { Is proposed new program } \\
\text { financially and } \\
\text { academically viable, if we } \\
\text { include the indirect costs } \\
\text { and lead-times needed } \\
\text { for workarounds to } \\
\text { standard calendar? }\end{array}$ & $\begin{array}{l}\text { Direct \& indirect costs of } \\
\text { new program intro. } \\
\text { estimated using activity- } \\
\text { framework from ep. } 5 \text {. } \\
\text { Lead-times for planning } \\
\text { incorporated from prior } \\
\text { process mapping }\end{array}$ & $\begin{array}{l}\text { Enterprise System } \\
\text { integrates standard } \\
\text { procedures \& } \\
\text { templates. Informal } \\
\text { cost estimate now used } \\
\text { to predict financial } \\
\text { viability of program. }\end{array}$ \\
\hline
\end{tabular}


Because this misalignment threatened the core of the organization's deep structure (its ability to award degrees), resources at all levels were mobilized and the Taskforce was able to define new processes and standards very rapidly. One might argue that the rapid response resulted from the generative design enacted in previous episodes of distributed, experiential learning. Taskforce members had internalized the operation of the deep structures needed to coordinate business and information processes across domain boundaries, which allowed them to react quickly in a crisis. The difference in the magnitude of change and the rapidity of response might explain why major critical incidents are viewed as resulting mainly from external pressures [4,6,8,12]

\subsection{Multiple layers of framing interaction}

This section explores [RQ2] What is the process by which design team participants collaborate in framing, exploring, and agreeing design problems and solutions? The coordinated, distributed cognition observed here operated at three levels of analysis:

A “primary generator” model. Darke, in her studies of architectural design noted the organizing power exercised by an abstraction of the expected solutionstructure, which she termed the "primary generator" of design. For example, architects might agree that they were designing a ranch house. This provided a framework to coordinate the work that followed [13]. The generative framework was provided in this study by agreeing a collective objective of mapping out the processes of new academic program creation. Even though group models and individual requirements for these processes changed throughout the design, Taskforce members used their process model to define how administrative work was coordinated across organizational domains, permitting a division of design labor that was retained throughout the project. The primary generator framework appeared to mediate knowledge translations across the boundaries of each admin. group's participation framework, by placing interactions within a known situation and sequence, so the design group could contextualize who-knows-what and who-does-what.

Coordinating objects or representations. A series of coordinating objects, discussed above, reflected the current problem frame for each episode. Each coordinating object incorporated the problemstructures of the previous one, complicating the structure to reflect an emergent design scope and boundary. These structures therefore appeared to play the role of epistemic objects [13], creating emergent models of reality that allowed misalignments with the deep structures of organization to be realized.

Individual problem-frames. Individuals surfaced implicit frames that represented requirements for an IS solution frequently in design meetings. It soon became clear that these often conflicted with the group's shared understanding of the problemsituation. Debate around application of the current coordinating object exposed misalignments between internalized deep structures - understood only in part by individuals - and the surface structures represented in the fragmented requirements for a design solution that the group produced, resulting in breakdowns.

A breakdown [15] occurs when our habitual practice - our seamless "being in the world" - is interrupted by the need to reflect on why things did not work as expected. "Breakdowns serve an extremely important cognitive function, revealing to us the nature of our practices and equipment, making them 'present-to-hand' to us" [14, pp. 77-78]. The deep structures of a problem-situation are revealed only when we stop to puzzle over why a process or tool did not produce the expected outcome. While a breakdown is generally conceptualized as a cognitive (individual) phenomenon, the interaction effects seen here suggest that a collective breakdown results when design group participants simultaneously realize that their shared understanding is insufficient to incorporate all of their implicit requirements for a solution. At this point, they coordinate argumentation around an epistemic object that allows them to explore their concerns [9] while presenting a sufficiently abstract boundary object [10] that it can coordinate knowledge across the network of interlocking participation frameworks represented by design group members [2]. When disagreements reach a critical mass, such that group consensus around the coordinating object can no longer be relied upon, the coordinating object is complexified to incorporate a wider range of concerns, while still being defined at a sufficiently vague level of abstraction that it can operate as a boundary object to mediate domainspecific participation frameworks [10]. Each coordinating object thus creates an expanded space for learning about the problem-structure that allows design participants to translate observed actions into the new systems of activity required [5].

The model of punctuated equilibrium that results is shown in Figure 4, demonstrating how three distinct levels of collective understanding interact to support the processes of boundary-spanning design. Collective breakdowns occur when a critical mass of dissonance forms around the coordinating object. Table 3 reveals that the realization of critical levels of dissonance is triggered by managerial reviews that expose operational problems in the design or by external threats to the organization. The subsequent process of reframing the problem-space is productive for design, as it complexifies the emergent group understanding through the distributed experiential learning shown in Figure 3 and the interaction effects shown in Figure 4. 


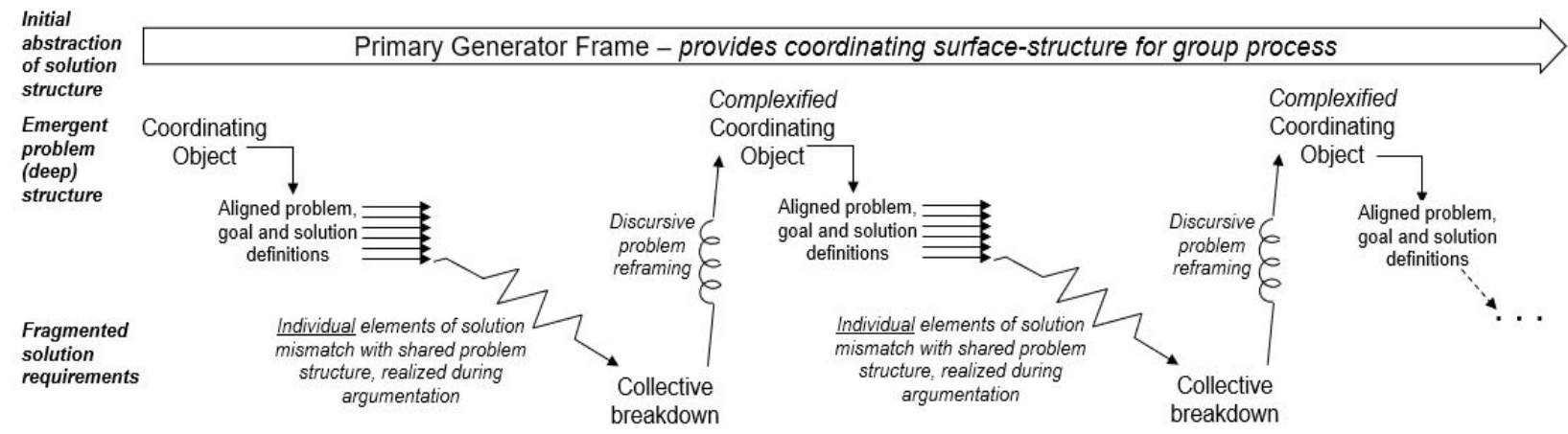

Figure 4. Layers of Framing in Complex Design

\section{Conclusions}

The contribution of this study is to present a model and detailed explanation of how boundaryspanning, complex systems design proceeds through a process of punctuated equilibrium. While interaction effects between individual, group, and generically subjective levels were noted by Drazin et al. [11] in their study of organizational innovation, this study presents exposes interactions between multiple levels of cognition within a network of interlocking participation frameworks [2]. The role of surface structures as providing an interface to deep structures via Information Systems design has been noted in the design science literature [5]. These findings suggests that the individual framing of surface structures that occurs when implicit IS solution requirements are surfaced, plays a key role in collective learning, as these misalign with collective representations of organizational deep structures (coordinating objects). The collective breakdowns that ensue act productively by refocusing design attention on a more complex representation of the problem-space, that increases shared understanding of the design problem.

The implications for research are that we need to explore interaction effects between collective and individual design-framing in more detail, to understand how a design group's network of interlocking participation frameworks enables emergent, individual framing of (solution-space) IS requirements, in particular what indicates design closure. The implications for practice are that we might productively employ a spiral process model for IS design that intentionally triggers a collective breakdown in each iteration. In boundary-spanning design contexts, we need to move the emphasis from goal-driven design to problem-focused exploration, as requirements for the IS solution appear to "fall out of" process-iterations that build to provide a sufficiently complex definition of deep structures in the problemspace for the design group to construct a complex, systemic solution.

\section{References}

[1] Jarke, M. and Lyytinen, K., "Complexity of Systems Evolution: Requirements Engineering Perspective", ACM Trans. on Mgt. Info. Systems (TMIS), 5(3), 2015, pp. 11.

[2] Engeström, Y., Engeström, R., and Karkkainen, M., "Polycontextuality and boundary crossing in expert cognition: Learning and problem solving in complex work activities", Learning \& Instruction, 5(4), 1995, pp. 319-336. [3] Davidson, E.J., "Technology Frames and Framing: A SocioCognitive Investigation of Requirements Determination" MIS Quarterly 26(4), 2002, pp.329-358.

[4] Gersick, C.J.G., "Reflections on Revolutionary Change", Journal of Change Management, 20(1), 2020, pp. 7-23.

[5] Harder Fischer, L. and Baskerville, R. "Socio-Technical Change: The Equilibrium Paradox", European Conference on Information Systems (ECIS), 2018, pp. 22.

[6] Silva, L. and Hirschheim, R., "Fighting Against Windmills: Strategic Information Systems and Organizational Deep Structures", MIS Quarterly, 31(2), 2007, pp. 327-354.

[7] Weick, K.E., Sensemaking In Organizations, Sage, Thousand Oaks CA, 1995.

[8] Lyytinen, K. and Newman, M., "Explaining information systems change: a punctuated socio-technical change model", Eur. J. of Info. Systems, 17(6), 2008, pp. 589-613.

[9] Knorr Cetina, K.D., Epistemic Cultures: How the Sciences Make Knowledge, Harvard Univ. Press, Cambridge, MA, 1999.

[10] Star, S., L., "The Structure of Ill-Structured Solutions: Boundary Objects and Heterogeneous Distributed Problem Solving", in M. Hubs and L. Gasser, (eds.): Readings in Distributed Artificial Intelligence 3, Morgan Kaufmann, Menlo Park, CA, 1989.

[11] Drazin, R., Glynn, M.A., and Kazanjian, R.K., "Multilevel theorizing about creativity in organizations: A sensemaking perspective", Academy of Management Review, 24(2), 1999, pp. 286-307.

[12] Gersick, C.J.G., "Revolutionary Change Theories: A Multilevel Exploration of the Punctuated Equilibrium Paradigm," Acad. of Mgt. Review, 16(1), 1991, pp. 10-36.

[13] Darke, J. "The Primary Generator And The Design Process", Design Studies 1(1), 1979, pp.36-44.

[14] Winograd, T. and Flores, F., Understanding Computers And Cognition, Ablex Corporation, Norwood, NJ, 1986.

[15] Heidegger, M., Being and Time, Harper \& Row New York, New York NY, 1962. 